fetuses during January 2012 in Policlinico Abano Terme, Abano Terme, Italy. Cord arterial blood gas parameters and hematocrit (Htc) were compared to the reference values obtained in 50 healthy, control neonates, matched for gestational age, vaginally delivered by 'one-step' approach. Data analysis was performed with SPSS for Windows statistical package (version 13).

Results In our study population, head-to-body interval was timed and was always inferior to 3 minutes. The groups had similar demographic and biomedical characteristics at baseline. The mean cord artery hematocrit (Hct 50.2 vs. 44.9; $\mathrm{p}<0.001$ ) levels were significantly higher in the head-to-body interval 'two-step' approach group, but there was no significant difference in the umbilical artery pH (7.30 vs. 7.29; $\mathrm{p}=0.45)$.

Conclusion Head-to-body delivery by 'two-step' approach increases the red cell mass in term infants and does not increase the risk of neonatal academia.

\section{LATE CORD-CLAMPING IMPROVES CIRCULATION IN NEONATES}

doi:10.1136/archdischild-2012-302724.0019

M Nelle, KN Walter, R Gerull. Divison of Neonatology, University Childrens Hospital Berne, Berne, Switzerland

Aim was to investigate the effects of late vs. early cord clamping on systemic circulation cerebral blood flow velocity (CBFV) in prematures infants $<1500 \mathrm{~g}$ in a randomized trial.

Subjects 35 neonates were studied 4 hours after caesarean section. In 19 neonates (birth weight: $1140 \pm 240$ g; gestational age: $29.0 \pm 2$ wks) the umbilical cords were clamped after 30 seconds and the infants were placed $30 \mathrm{~cm}$ below placenta level (LCC), and in 16 $(1180 \pm 270 \mathrm{~g} ; 28.6 \pm 2 \mathrm{wks})$ the cords were clamped immediately (ECC).

Methods MBP (mmHg), left ventricular output (LVO, $\mathrm{ml} / \mathrm{kg}$ / $\mathrm{min}$ ), mean cerebral blood flow velocity (CBFV) in the Arteria carotis interna (ACI, m/s; Doppler), hemoglobin ( $\mathrm{Hb}, \mathrm{g} / \mathrm{dl}$ ), and hematocrit $(\mathrm{Hct}, \%)$ were measured. Systemic and cerebral hemoglobin transport (HbT), systemic vascular resistance (SVR; $\mathrm{mmHg} / \mathrm{kg}$ / $\left.\min ^{-1}\right)$ were estimated. Statistic: *unpaared t-test.

\section{Abstract 19 Table 1}

\begin{tabular}{lccc}
\hline Results & ECC & LCC & p-value \\
\hline MBP & $34 \pm 3$ & $45 \pm 7$ & 0.03 \\
LVO & $229 \pm 44$ & $258 \pm 36$ & $n s$ \\
ACA & $0.15 \pm 0.03$ & $0.21 \pm 0.05$ & ns \\
SVR & $123 \pm 40$ & $145 \pm 30$ & 0.05 \\
Hct & $0.44 \pm 0.4$ & $0.56 \pm 0.5$ & 0.002 \\
cerebral HbT & $7.4 \pm 1.8$ & $11.1 \pm 4.1$ & 0.04 \\
systemic HbT & $154 \pm 27$ & $181 \pm 24$ & 0.05 \\
\hline
\end{tabular}

Conclusions Late cord clamping improves blood pressure, systemic vascular resistance, hemoglobin, systemic and cerebral hemoglobin transport. The ECC group required more volume expansion in the first $24 \mathrm{~h}$ (ECC: 12/16, 14 $\pm 7 \mathrm{ml} / \mathrm{kg}$; LCC: $6 / 19,5 \pm 4 \mathrm{ml} / \mathrm{kg}$; $\mathrm{p}<0.03)$.

\section{DELAYED VERSUS EARLY UMBILICAL CORD CLAMPING: DEVELOPMENTAL OUTCOMES AT 4 MONTHS IN SWEDISH INFANTS}

doi:10.1136/archdischild-2012-302724.0020

1,20 Andersson, ${ }^{1} \mathrm{~A}$ Kasemo, ${ }^{3} \mathrm{M}$ Domellöf, ${ }^{2} \mathrm{~L}$ Hellström-Westas. ${ }^{1}$ Pediatrics, Hallands Sjukhus, Halmstad; '2Department of Women's and Children's Health, Uppsala University, Uppsala; ${ }^{3}$ Department of Clinical Sciences, Pediatrics, Umeå University, Umeå, Sweden
Background Delayed cord clamping is associated with increased neonatal hemoglobin levels, and improved iron status in infants at 4-6 months. There are no previous studies evaluating effects from timing of clamping on development in term infants.

Objective Does the time for umbilical cord clamping affect psychomotor development evaluated with Ages and Stages Questionnaire (ASQ) in 4-month infants?

Design/methods Randomized controlled trial investigating effect of delayed cord clamping ( $\geq 180 \mathrm{sec}$, DCC) versus early cord clamping ( $\leq 10 \mathrm{sec}, \mathrm{ECC})$ in 382 full-term normal deliveries. After 4 months, parents reported their infant's development by the ASO.

Results 365 (96\%) questionnaires were returned. The mean total ASO score did not differ between groups. The DCC group had a higher mean score (SD) in the domain problem solving, 55.3 (7.2) vs. 53.5 (8.2), $\mathrm{p}=0.03$ and a lower score in personal-social; 49.5 (9.3) vs. 51.8 (8.1), $\mathrm{p}=0.01$. There were no difference between the DCC and ECC groups concerning the frequency of infants under cut-off score (table).

Abstract 20 Table 1

\begin{tabular}{llll}
\hline & DCC $\mathbf{n}(\%)$ & ECC $\mathbf{n}(\%)$ & $\mathbf{p}$ \\
\hline Communication $<33.3$ & $4(2.2)$ & $4(2.2)$ & 1.0 \\
Gross motor $<40.1$ & $17(9.2)$ & $19(10.6)$ & 0.7 \\
Fine motor $<27.5$ & $6(3.2)$ & $12(6.7)$ & 0.15 \\
Problem solving $<35$ & $3(1.6)$ & $7(3.9)$ & 0.21 \\
Personal-social $<33$ & $8(4.3)$ & $8(4.4)$ & 1.0 \\
\hline
\end{tabular}

Infants below cut off score in ASQ domains at 4 mo

Conclusions There was no overall effect of DCC on neurodevelopment assessed at 4 months of age. The possible effects on the domains will be further investigated in a follow-up study.

\section{DELAYED CORD CLAMPING IN PRETERM INFANTS $<32$ WEEKS OF GESTATION): CURRENT CLINICAL PRACTICE IN THE UNITED KINGDOM}

doi:10.1136/archdischild-2012-302724.0021

1,2Y Singh, ${ }^{2}$ S Oddie. ${ }^{1}$ Neonatal Medicine, The Leeds Teaching Hospitals NHS Trust, Leeds; ${ }^{2}$ Neonatal Medicine, Bradford Teaching Hospitals, Bradford, UK

Background Resuscitation guidelines recommend delayed cord clamping in term infants and this practice is being widely adopted in the UK. But there are no clear recommendations for early or delayed cord clamping in preterm infants.

Aims and objectives To find out the current UK clinical practice in early or delayed cord clamping in the preterm infants.

Study Design and methods Questionnaire based study carried out via internet tool (SurveyMonkey) followed by telephone interview from non-responders. Questionnaire completed by consultants, registrars or senior neonatal sisters (band 6 and above).

Results $100 \%$ response rate from all the 222 units providing neonatal care in the UK. Currently 24\% units (52 of 222 units) delay cord clamping or practice other means to facilitate placental transfusion in preterm infants while $63 \%$ units have early cord clamping practice and no response from $8 \%$ units.

$46 \%$ (24 of 52 units) delay cord clamping for 31-60 seconds, $17 \%$ delay for $<30$ seconds, $14 \%$ delay for $61-120$ seconds and $2 \%$ delay for 121-180 seconds. $8 \%$ units (4 of 52 units) practise cord milking to facilitate placental transfusion while $13 \%$ provided other means of facilitating placental transfusion.

Conclusion Current clinical practice in cord clamping in preterm infants varies significantly in the UK. Despite research showing benefits without any significant adverse effects only $24 \%$ units delay cord clamping or use others means to facilitate placental transfusion. A randomised control trial is needed to provide further 